\title{
A humanização e o palhaço: entre significados e sorrisos
}

\author{
The humanization and the clown: between meanings and smiles \\ La humanización y el payaso: entre significados y sonrisas
}

Recebido: 27/01/2022 | Revisado: 03/02/2022 | Aceito: 04/02/2022 | Publicado: 06/02/2022

\author{
Tássio Cunha Paes da Costa \\ ORCID: https://orcid.org/0000-0001-7320-6286 \\ Terapeuta Ocupacional, Brasil \\ E-mail: tassio.cunha@hotmail.com \\ Amanda Vieira Soares Cunha \\ ORCID: https://orcid.org/0000-0003-3969-417X \\ Terapeuta Ocupacional, Brasil \\ E-mail: mandaviso.to@gmail.com \\ Ivan Elias de Azevedo \\ ORCID: https://orcid.org/0000-0001-9408-1072 \\ Universidade Federal de Sergipe \\ E-mail: azevedo.ivan@gmail.com \\ Raphaela Schiassi Hernandes \\ ORCID: https://orcid.org/0000-0002-9290-1003 \\ Universidade Federal de Sergipe, Brasil \\ E-mail: rapha_to@hotmail.com
}

\begin{abstract}
Resumo
A humanização se insere no campo da saúde como um recurso imprescindível nas práticas. Dentro do leque de agentes que possibilitam este processo, o palhaço se põe como fomentador da humanização. Foi realizada uma pesquisa em um hospital no interior do estado de Sergipe, onde os dados foram coletados no ano de 2018, por meio de entrevista que aconteceu após intervenções dos palhaços, integrantes do projeto Território Feliz. O objetivo geral da pesquisa é compreender o significado da humanização no contexto hospitalar, para diferentes atores, por meio da atuação do palhaço. A análise de dados foi feita por meio da abordagem Sócio-Histórica. Como resultado observou que o significado de humanização está intrinsicamente ligado ao âmbito das relações humanas, envolvendo a compreensão da ética, dos valores e das relações com o meio em que os sujeitos estão inseridos, sendo que um dos grandes obstáculos para que a humanização aconteça é a exclusão da singularidade dos sujeitos e de suas potencialidades como promotoras de saúde. Neste sentido, ressalta a urgência de inserir a humanização nos ambientes hospitalares, onde, as relações se mostram fragilizadas, distantes e permeadas pela lógica do trabalho, engessada em práticas e ações técnicas que visam apenas acabar com a doença.
\end{abstract}

Palavras-chave: Hospitalização; Humanização; Riso.

\begin{abstract}
Humanization is inserted in the health field as an essential resource in practices. Within the range of agents that make this process possible, the palazzo stands out as a promoter of humanization. A survey was carried out in a hospital outside the state of Sergipe, where data were collected in 2018, through an interview that was carried out after the interventions of two patients, members of the Território Feliz project. The general objective of the research is to understand the meaning of humanization in the hospital context, for different actors, through the attitude of the patient. Data analysis was performed using the Socio-Historical approach. As a result, I observed that the sense of humanization is intrinsically linked to the field of human relations, involving the understanding of ethics, two values and relationships as a means in which subjects are inserted, and these two great obstacles to humanization Place, place. the singularity of two subjects and their potential as health promoters occur without exclusion. In this sense, it highlights the urgency of inserting humanization in hospital environments, where relationships are fragile, distant and permeated by the logic of work, engendered by practices and technical actions whose only purpose is care.
\end{abstract}

Keywords: Hospitalization; Humanization; Laughter.

\section{Resumen}

La humanización se inserta en el campo de la salud como recurso esencial en las prácticas. Dentro del abanico de agentes que hacen posible este proceso, el palazzo se destaca como promotor de la humanización. Se realizó una encuesta en un hospital fuera del estado de Sergipe, donde se recolectaron datos en 2018, a través de una entrevista que se realizó después de las intervenciones de dos pacientes, miembros del proyecto Territorio Feliz. El objetivo general de la investigación es comprender el significado de la humanización en el contexto hospitalario, para diferentes actores, a través de la actitud del paciente. El análisis de los datos se realizó utilizando el enfoque Socio-Histórico. Como 
resultado, observé que el sentido de la humanización está intrínsecamente ligado al ámbito de las relaciones humanas, involucrando la comprensión de la ética, dos valores y las relaciones como el medio en el que se insertan los sujetos, y estos dos grandes obstáculos para que la humanización se lleve a cabo. se producen son exclusión la singularidad de dos sujetos y su potencial como promotores de salud. En ese sentido, destaca la urgencia de insertar la humanización en los ambientes hospitalarios, donde las relaciones son frágiles, distantes y permeadas por la lógica del trabajo, engendradas por prácticas y acciones técnicas que tienen como único fin el cuidado.

Palabras clave: Hospitalización; Humanización; Risa.

\section{Introdução}

A Saúde e a Doença são eventos que perpassam por toda a história da humanidade, seus conceitos mostram-se intrinsicamente ligados no campo de discussão teórica e prática, não existindo uma conceituação universal. Albuquerque \& Oliveira (2002) apontam que para esta discussão ser fomentada se faz necessário a compreensão das construções de significados sobre as forças da natureza, sobre as funções do corpo e sua estrutura, assim como a espiritualidade humana e a relação com o ambiente. Historicamente, duas concepções marcam o trajeto da medicina até os dias atuais, uma delas é a concepção fisiológica de Hipócrates, onde a origem da doença é o desequilíbrio entre as forças naturais internas e externas ao ser humano, que concentra a percepção de saúde e doença na pessoa como um todo, evitando associar doenças a algum órgão de maneira isolada. Outra percepção é a ontológica, onde a percepção de doença vem de fora do organismo, nessa perspectiva a doença é uma entidade externa que invade e se instala no corpo, com a característica mágica/religiosa. Estas entidades podem ter diferentes significados, dependendo da origem étnica, cultural, geográfica e histórica. A concepção ontológica está ligada à identificação da doença por órgãos ou partes do corpo, buscando um diagnóstico exato, caracterizando a doença como uma coisa própria, sem relação com a personalidade, modo de vida ou características físicas do indivíduo.

Canguilhem (2009) sugestiona que esta ótica mágica/religiosa é encorajadora, assim, o caminho de entrada da doença, seja por algum tipo de possessão, ou por algum castigo, é o mesmo caminho de saída, possibilitando a cura de maneira mais favorável.

Ao final da Idade Média, Backes et al. (2009) apontam que o surgimento do Renascimento faz com que as ideias acerca da doença fossem mais plausíveis e cabíveis de justificativa e que conseguisse responder de maneira direta sobre os agentes patológicos, sendo necessário ressaltar que foi uma época que existiu avanços em conhecimentos químicos e mecânicos (Scliar, 2007).

A mudança destes conceitos influenciava toda a saúde nas esferas individual, coletiva e institucional. Batistella (2007) aponta que esta transformação alterou completamente o conceito de saúde e a função hospitalar, saindo de uma hegemonia religiosa para uma preeminência médica, na qual todos seus aparatos vão em busca de explicações e soluções mais realísticas. supremacia religiosa para uma supremacia médica, na qual todos seus aparatos vão em busca de explicações e soluções mais realísticas.

Um momento fundamental acontece após a Segunda Guerra Mundial, neste período, no campo da Saúde ocorreu um distanciamento ainda maior das práticas e políticas de saúde pública com as ações da medicina curativa, para uma assistência médica centrada em práticas hospitalares que visando a reabilitação, fragmentava os cuidados e consequentemente refletia num ensino fragmentado e cada vez mais especializado.

Com o fim da Segunda Guerra Mundial, e com todos os reflexos desta, foi criada a Organização das Nações Unidas (ONU), consequentemente, foram criados órgãos especializados em diversas áreas, a Organização Mundial da Saúde (OMS) é um destes órgãos, que tem publicado em sua constituição que a "saúde é um estado de completo bem-estar físico, mental e social, e não consiste apenas na ausência de doença ou de enfermidade" (OMS, 1946, p. 1).

Batistella (2007) aponta que este novo conceito veio para "derrubar" o sentido negativo que a saúde adquiriu dentre os séculos XVII e XIX, trazendo consigo críticas relacionadas ao caráter “inalcançável” deste perfil de saúde. 
Seguindo a linha histórica da conceituação Saúde e Doença, um dos pontos chaves para a realidade Brasileira e mundial foi a VIII Conferência Nacional de Saúde (CNS), realizada de 17 a 21 de março de 1986. Esta se encontra como fato histórico, pois, além de abordar um "conceito ampliado", foi fruto de uma mudança de pensamento social por parte da população brasileira. Logo no início do relatório final que nasceu na VIII CNS, a saúde é abordada como:

Resultante das condições de alimentação, habitação, educação, renda, meio ambiente, trabalho, transporte, emprego, lazer, liberdade, acesso e posse da terra e acesso aos serviços de saúde. Sendo assim, é principalmente resultado das formas de organização social, de produção, as quais podem gerar grandes desigualdades nos níveis de vida (Brasil, 1986, p. 4).

Um dos grandes feitos desta conceituação foi trazer a Saúde e Doença para perto de determinantes sociais, com isso, amplia-se os olhares para além do indivíduo doente e do agente patológico. Considerando estes aspectos históricos, Czeresnia (2003) traz que a humanidade percorreu duas linhas de pensamentos opostos, uma destas voltada para a redução, e a outra tendo como base a abrangência. Sendo assim, a autora apresenta que o caminho científico foi trilhado em bases reducionistas.

Dentro desta visão, as patologias foram e são utilizadas para descrever achados clínicos, voltando totalmente ou quase totalmente o olhar para o aspecto patológico do indivíduo. Portanto, para Cutolo (2006) o padrão biomédico atual é marcado pela investigação de fatores específicos ligados pelo biologicismo, no qual apenas a explicação uni casual é aceita, resultando num cuidado que não é satisfatório.

A partir de toda insuficiência no cuidado à saúde, passam a ser pensado outros modelos que ponderem a saúde de modo que consigam abranger os diversos determinantes do indivíduo e seguir o caminho oposto trilhado pela "desumanização".

Neste sentido, ações humanizadoras iniciaram-se nos hospitais públicos, originadas pela mobilização de grupos sociais, que reivindicavam melhorias na qualidade dos serviços de saúde pública. Foi através destas mobilizações que algumas revindicações começaram a se concretizar. Inicialmente, eram ações que tornavam o ambiente hospitalar mais acolhedor: atividades lúdicas, lazer, arte, entretenimento, melhorias dos serviços (Rios, 2009).

Porém, é necessário ressaltar que não existiram grandes mudanças no contexto hospitalar, já que, o modelo predominante continuava sendo o biomédico e toda a sua lógica estava inserida intimamente em todo pensamento de saúde. Para tanto, começa a existir uma mudança de pensamento e de prática ética por parte dos profissionais, além de uma modificação social de cunho organizativo das ações, por ganhos de direitos por parte do povo.

Um dos atos desta humanização se encontra no ano de 2001, quando o Governo Federal lança o Programa Nacional de Humanização da Assistência Hospitalar (PNHAH) com o objetivo de "promover uma mudança de cultura no atendimento de saúde no hospital (Serra, 2001, p. 9). Esta medida foi tomada em um contexto de muitos relatos de maus tratos dentro da rede hospitalar, e seu objetivo principal era melhorar as interrelações de profissionais e pacientes, visando a melhor qualidade no atendimento à saúde, melhor qualidade no atendimento ao usuário e melhores condições de trabalhos para todos os profissionais.

Rios (2009) traz que, isoladamente, foram feitas diversas ações em hospitais públicos, porém, sem mudanças estruturais, na organização do trabalho ou no cuidado com o paciente. Com isso, o papel que essas ações realizavam eram de amenização de um contexto hierárquico e limitante, mas que aos poucos foi surtindo efeito.

Outra importante ação para a humanização no Brasil aconteceu com a criação da Política Nacional de Humanização em 2004, na qual, de maneira mais concreta a humanização é pensada para ser posta em prática de acordo com um Sistema Único de Saúde (SUS). Segundo o caderno de textos, do HumanizaSUS (2004): "Humanizar é, então, ofertar atendimento de 
qualidade articulando os avanços tecnológicos com acolhimento, com melhoria dos ambientes de cuidado e das condições de trabalho dos profissionais" (p. 6).

Essa forma de atendimento leva em consideração a co-gestão no processo de cuidado, que garante uma participação ativa de todos os sujeitos em relação a sua saúde, sendo capazes de modificar a sua realidade, seja enquanto usuário ou profissional (Humanizasus, 2004). A humanização para Rios (2009) se mostra enquanto a compreensão do indivíduo atrelada a valorização deste e de tudo que ele traz, respeitando o sujeito em sua complexidade, favorecendo a co-gestão, buscando uma mudança de cunho ético que transformará as ações práticas e de gestão.

Esta mudança de perfil expressa então uma alteração estrutural que foi proposta para todo o sistema de saúde e consequentemente para profissionais, gestores e pacientes. Representa uma ampliação do olhar para aquilo que é tido como Saúde e um reconhecimento das limitações do modelo biomédico vigente.

Portanto, o Ministério da Saúde (2008) passa a enxergar a humanização enquanto política transversal e que esta seria a possibilidade de trazer para a prática os princípios do Sistema Único de Saúde, em seus diversos aspectos de gestão e operação da rede de saúde em seus dispositivos legais. Desse modo o SUS e todos os seus agentes devem passar a compreender a humanização como:

Valorização dos diferentes sujeitos implicados no processo de produção de saúde: usuários, trabalhadores e gestores; Fomento da autonomia e do protagonismo desses sujeitos e dos coletivos; Aumento do grau de co-responsabilidade na produção de saúde e de sujeitos; Estabelecimento de vínculos solidários e de participação coletiva no processo de gestão; Mapeamento e interação com as demandas sociais, coletivas e subjetivas de saúde; Defesa de um SUS que reconhece a diversidade do povo brasileiro e a todos oferece a mesma atenção à saúde, sem distinção de idade, raça/ cor, origem, gênero e orientação sexual (HumanizaSUS, 2010, p.18)

Dessa forma, a interação entre profissionais e pacientes se mostra como um caminho oportuno para a produção da saúde, o respeito dos saberes e o nivelamento institucional pode vir a permitir ações que além de mobilizar os sujeitos, garantirão uma prática mais fidedigna as necessidades que inúmeras vezes são sobrepostas pelas vontades dos profissionais.

Por fim, a humanização pode ser entendida como o respeito para com os sujeitos e com isto, a valorização dos diversos saberes e a participação do indivíduo no coletivo, perpassando por mudanças éticas, culturais e históricas da forma que se enxerga o outro e o processo Saúde e Doença, respeitando a pluralidade que se é necessária para compreender os diversos fatores influenciadores (Rios, 2009).

A partir desta pesquisa, tentar-se-á entender como ocorre este processo de humanização, de que forma ele pode ser influenciado e como ele pode influenciar na rotina do contexto hospitalar, tanto para profissionais, familiares e pacientes. Para tanto, a ferramenta principal foi Palhaço. Tal figura está, presente em todas as culturas e épocas e por meio do riso consegue aliviar tensões e externalizar potenciais das pessoas que se encontram em uma internação hospitalar, familiares dessas e trabalhadores deste local.

O palhaço, pela maioria das pessoas, se originou nos circos, mas acreditar que a figura do palhaço, é exclusiva do circo é negar uma história muito antiga, pois a arte do palhaço é milenar, ela estava presente desde os saltimbancos mais remotos e artistas circenses diversos. Neste sentido, a figura do palhaço se fazia presente por meio de feiticeiros das tribos indígenas que usava do riso como tratamento, visando a melhora do humor e até a cura de enfermidades (De Castro, 2005).

Perante a toda gama de locais de atuação para o palhaço, a sua entrada no contexto hospitalar se mostra enquanto recente. De Ayalla Rodrigues e Nunes Filho (2013) traz como exemplo a iniciativa do Michael Christensen, diretor circense em Nova York, que no ano de 1986 levou a arte do palhaço para dentro do hospital. No Brasil, muitos palhaços visitavam hospitais, mas de maneira informal. Em 1991 a abordagem de pacientes por palhaços de hospital começou pela Organização não Governamental, Doutores da Alegria. 
A figura do palhaço então se faz presente até hoje por grupos que se espalham em diversos hospitais, buscando levar aos enfermos uma atenção mais totalitária. Para De Ayalla Rodrigues \& Nunes Filho (2013), o palhaço consegue transmitir um olhar mais atento ao indivíduo e a sua condição geral que se encontra no leito e em todo o seu contexto, o palhaço neste sentido, proporciona a mudança de visão patológica do indivíduo para um olhar nas potencialidades, mesmo que impossibilitado pelo contexto.

Portanto, o palhaço para Junior (2011) se mostra como a expressão do subjetivo do indivíduo, o particular compartilhado com o coletivo, que utiliza do riso e do que for mais excêntrico como ferramenta de subversão. Thebas (2005) corrobora com esta visão quando afirma que o certo e o errado para o palhaço se mostram enquanto subjetivo e abstrato, ou seja, quando o tema é palhaço não existe uma única verdade, mas uma multiplicidade de figuras, de tipos, de espaços, de poéticas e de nomes, independentemente de quaisquer opiniões, paixões e preferências pessoais.

Neste sentido a presença do palhaço no hospital se faz necessária devido ao processo de hospitalização, que para o indivíduo é muito danoso. Graças (1997) aponta que dentro do contexto hospitalar ocorre a ruptura de laços e atividades sociais, o paciente torna-se sujeito a intervenções invasivas e que por muitas das vezes vem acompanhada por um relacionamento distanciado para com os profissionais que o enxergam e classificam enquanto sua patologia. $\mathrm{O}$ ambiente de paredes de cores frias, mórbidas, não reflete a vida que existe fora deste contexto e esconde a vida que o paciente tem neste local, sendo a invisibilidade e a subjetividade do sujeito apagada.

Além disso, a autora acima citada explicita a perda de autonomia do paciente, onde, para além de todas as alterações fisiológicas que resultaram no processo de doença, os padrões habituais de comportamento são muitas das vezes impostos pela equipe, sendo até suprimida as vontades e o direito de escolha do paciente sobre como ser tratado.

Sendo assim, a presença do palhaço no hospital surge como uma vertente possível a ser utilizada. A autora Masetti (2005) aponta que o palhaço tem autonomia para trabalhar dentro da sua lógica, que surge em pensamentos que são opostos ao que sempre é proposto neste ambiente. Autonomia esta que transcende da lógica superficial de cuidado a determinada patologia e parte para um mergulho de cabeça no subjetivo do indivíduo, onde lhes é reconhecido o direito de propor novas coisas, criar novas histórias e resinificar sua estadia no hospital.

Faz-se necessário entender então que para que estas transformações aconteçam, não existe uma fórmula fechada para a atuação do palhaço, De Ayalla Rodrigues e Nunes Filho (2013), apontam que os únicos critérios que são mais apresentados para a permissão da atuação do palhaço é a aceitação da ação por parte dos pacientes, cuidadores e profissionais, sendo assim, tudo aquilo que provoque o prazer do riso é válido, e tendo este elemento enquanto principal objetivo.

De Castro (2005) aponta a importância do riso e de que forma o palhaço utiliza. Segundo a autora, o riso se encontra neste sentido como sinônimo de prazer e somente por ele ser bom é o fundamental, não se fazendo necessária explicação para ele. A partir da figura do palhaço e de suas estripulias o riso vem de maneira livre, descabida de julgamentos, da mesma forma que são as ações do palhaço, que consequentemente leva a aquele ambiente um clima mais descontraído, mais humano, onde, a experiência do humor provocada pelo palhaço permite enxergar o indivíduo dissociado do seu estado patológico e permite ao paciente relacionar-se com o seu próprio corpo, pensamento e vontades, valorizando então a sua capacidade particular, sua individualidade.

Por fim, De Ayalla Rodrigues e Nunes Filho (2013) apontam a importância da utilização do palhaço no contexto hospitalar, para eles o palhaço:

É como uma estratégia para um plano maior: a difusão de um ambiente hospitalar mais acessível e amoroso, até ao ponto em que ela estaria intrínseca à prática da Saúde com a perpetuação de um ambiente mais humanizado, de acordo com o que se espera dos médicos, enfermeiras ou técnicos em enfermagem de um hospital (p.78). 
Portanto, o objetivo geral dessa pesquisa é compreender o significado da humanização no contexto hospitalar, para diferentes atores, por meio da atuação do palhaço

\section{Percurso Metodológico}

A presente pesquisa se insere no paradigma qualitativo. Trabalhando a partir dos valores, crenças, hábitos, atitudes, representações e opiniões, visando utilizar das interligações do sujeito com o próximo e com o seu meio (Minayo \& Sanches, 1993). Neste sentido, a pesquisa aponta uma real necessidade em se utilizar deste tipo de metodologia, pois, no campo dos significados não é pertinente utilizar-se de reducionismos e números para expressar toda a complexidade e singularidade de cada sujeito e seus significados.

Este estudo tem seu aporte teórico-metodológico na psicologia sócio-histórica, que se sustenta principalmente nas ideias de Vygotsky, que tem uma concepção histórico-dialética de homem, visando a superação de concepções fundamentadas no empirismo e no individualismo. Deste modo, seu objetivo é estudar o homem enquanto personagem de um processo histórico, a partir de uma perspectiva de integração entre corpo e mente (Freitas, 2000).

Para Aguiar e Ozella (2006) a busca dos significados na pesquisa inicia-se pelo pensamento empírico e segue em direção a aquilo que não está evidente e que necessita ser explorado para chegarmos a compreensão dos processos da pesquisa, que estão ligados diretamente a formação sócio histórica do homem. Os significados, portanto, são constituídos socialmente e revelam valores morais, éticos e consensuais que se desenvolvem historicamente a partir de processos dinâmicos. Neste sentido, os significados possibilitam a comunicação e socialização das experiências pois são experiências compartilhadas e vivenciadas de modo individual e primordialmente coletivo.

Portanto, trabalhar com a pesquisa qualitativa numa abordagem sócio-histórica consiste numa preocupação de compreender os eventos investigados, descrevendo-os e procurando as suas possíveis relações, integrando o individual com o social (Freitas, 2000).

\subsection{Participantes da pesquisa}

A escolha dos participantes foi feita de forma aleatória dentro das alas e postos de trabalho. Os entrevistados foram divididos entre as categorias de: pacientes, familiares e profissionais da saúde pois podem surgir óticas diferentes de cada um destes. Os sujeitos só participaram da pesquisa após assinarem um Termo de Consentimento Livre e Esclarecido em duas vias, na qual uma ficou com o pesquisador e a outra com o sujeito.

Como critérios de inclusão, os participantes deveriam compreender aquilo que lhe era perguntado e conseguisse formular respostas completas, sendo necessário estar em condições mínimas cognitivas, emocionais e físicas para que respondessem a entrevista de maneira independente. Além disso, os entrevistados deveriam ter passado pela intervenção dos palhaços do Projeto Território Feliz. Foram entrevistados 14 pacientes e 15 acompanhantes que foram divididos para a Clínica Médica, Clínica Pediátrica e Pronto Socorro e 15 profissionais da saúde que estavam no hospital, totalizando 44 sujeitos, divididos nos três dias de intervenções.

\subsection{Local da pesquisa}

A pesquisa foi feita em um Hospital Universitário no interior do Estado de Sergipe. Segundo a Empresa Brasileira de Recursos Hospitalares (EBSERH, 2015), que gere este espaço de saúde, o hospital no ano de 2015 contava com 130 leitos, sendo que destes, 77 estavam ativos, 53 desativados e 12 voltados ao cuidado intensivo, existindo uma previsão para ativação destes 53 leitos a partir do ano de 2016. 
A estrutura física hospitalar se divide em recepção, sala de espera (azul e verde), Pronto socorro (Vermelha, Amarela e Reidratação), UTI, Clínica Médica, Clínica Cirúrgica, CME, Centro Cirúrgico, Clínica pediátrica, Farmácia e Administração. Segundo a EBSERH (2015), no serviço de Internação Hospitalar a ala da clínica médica possuía 12 enfermarias e na ala cirúrgica mais 11 enfermarias e cada enfermaria com 5 leitos. Estando previsto a abertura de 15 leitos de saúde mental.

No setor de urgência e emergência se configura enquanto porta aberta, estruturado em 05 consultórios, 1 sala de estabilização (vermelha com 3 leitos), 03 salas de observação com 13 leitos, 1 leito de isolamento e 1 sala de reidratação/ nebulização/ medicação com 48 poltronas.

\subsection{Aspectos éticos}

A pesquisa foi desenvolvida conforme as diretrizes da Resolução CNS 466/2012, com as atualizações disponíveis na Resolução CNS 510/2016, sendo que a principal questão ética dessa pesquisa refere-se à garantia de anonimato dos entrevistados, que será garantida em todas as publicações decorrentes da mesma, sendo compromisso assumido pelos pesquisadores. A pesquisa foi autorizada pelo Comitê de Ética e Pesquisa com o número de aprovação CAAE: 75159117.5.0000.5546.

\subsection{Procedimentos de coleta de dados}

Inicialmente os pesquisadores foram até o local que se daria a pesquisa a fim de explicar aos coordenadores do hospital os objetivos e sua forma de execução. Deixando no local a carta de autorização. Após a análise do Comitê de Ética foi dado início as intervenções e entrevistas. A entrevista foi feita pelo pesquisador e ocorreu momentos após as intervenções dos palhaços. Os depoimentos foram gravados e transcritos integralmente pelo pesquisador.

A entrevista continha cinco perguntas abertas.

"O que é saúde para você"?

"No seu entendimento o que seria a humanização?"

"O que é necessário para que esta humanização aconteça?"

"Qual o significado do palhaço no hospital?"

"Você consegue perceber alguma diferença com a presença do palhaço neste ambiente, se sim, o que muda?"

Segundo Freitas (2002), em uma pesquisa qualitativa com a perspectiva sócio-histórica, as entrevistas costumam ser marcadas pela característica dialógica, ou seja, não é apenas uma troca de perguntas e respostas, mas sim uma produção de linguagem, onde o significado está intrinsicamente ligado ao contexto. Na entrevista é o sujeito que se expressa, mas sua voz carrega o tom de outras vozes, refletindo a realidade de grupo, gênero, etnia, classe, momentos histórico e social.

Além das entrevistas, foram utilizadas intervenções com a figura do palhaço feito pelos concluintes do projeto Território Feliz que atuam no hospital, estas intervenções aconteceram quinzenalmente por um período de duas horas cada, formalizando 3 encontros. Somente após as intervenções que o pesquisador fez a entrevista com os sujeitos.

\subsection{Procedimento de análise dos dados}

A análise dos dados está embasada na abordagem sócio histórica, que se fundamenta no materialismo histórico e dialético. Esta essa abordagem baseia-se na tentativa de superar os reducionismos das concepções empiristas e idealistas. Com isso, Aguiar (2000) aponta que a tentativa da psicologia de entender o indivíduo em sua singularidade, não se torna sinônimo de redução do indivíduos em partes para facilitar o entendimento sobre este, mas sim, a partir da singularidade, compreender a 
relação do indivíduo do seu meio interno em contato com o externo e todas as correlações de expressão das condições históricas, sociais, interacionais que se mostram enquanto mutáveis a partir das expressões da vontade do indivíduo de edificar a sua existência.

Tendo o material gravado e transcrito, foram realizadas leituras "flutuantes", com o intuito de familiarizar e se apropriar dos conteúdos que deram base para a formação dos pré-indicadores. O critério básico que foi utilizado para filtrar esses pré-indicadores é verificar sua importância para a compreensão do objetivo da investigação. A partir das leituras flutuantes foram emergindo temas diversos, que se caracterizam pela maior frequência (pela sua repetição ou reiteração), importância que os sujeitos trazem nas falas, pela carga emocional presente e pelas ambivalências ou contradições (Aguiar \& Ozella, 2006).

Segundo os mesmos autores acima, os núcleos, por sua vez, expressam os pontos centrais e fundamentais que envolvam emocionalmente os sujeitos da pesquisa e apontam implicações diretas na compreensão dos sentidos e significados, além de revelar suas determinações constitutivas.

A análise dos núcleos não se restringe à fala de cada informante, haja vista que, a abordagem utilizada na pesquisa busca evitar a compreensão a partir dos reducionismos.

\section{Resultados e Discussão}

Dando continuidade ao processo de compreensão dos significados apontados pelos atores desta pesquisa, acerca da humanização, saúde e palhaço, inicia-se o processo de conversação dos indicadores para assim chegar a organização em núcleos de significação, estes que permitiram alcançar os pontos centrais que explicitam no sujeito a sua construção (Aguiar \& Ozella, 2006).

A análise dos dados surge a partir das entrevistas feitas no hospital aos pacientes, cuidadores e profissionais durante os três dias de encontro na unidade hospitalar. Foram realizadas 44 entrevistas das 45 previstas, onde, dos quinze pacientes esperados foi conseguido o número de quatorze disponíveis. Analiso então que essa única entrevista que não foi feita representa a tantos outros pacientes que em seu direito recusaram ou não conseguiram participar da pesquisa, mesmo demonstrando vontade. A partir dos pré-indicadores surgiram 23 (vinte e três) indicadores que articulados geraram três unidades temáticas subdivididas em 7 (sete) núcleos de significação.

Quadro 1. Núcleos de Significação.

\begin{tabular}{|l|l|}
\hline UNIDADES TEMÁTICAS & NÚCLEOS DE SIGNIFICAÇÃO \\
\hline A - Saúde, conceitos, diversidade... & a.1) Saúde: Bem-estar versus ausência de doença \\
\hline B - "Humanização, entre o querer, o poder e o fazer" & b.1) Humanização: Empatia e ética. \\
& b.2) É direito se sentir humanizado! \\
& b.3) Sem condições não dá! \\
\hline C - "E o palhaço com o seu nariz..." & $\begin{array}{l}\text { c.1) "O palhaço enquanto ferramenta da humanização" } \\
\text { c.2) O que estou sentindo Dr. Palhaço? } \\
\text { c.3) "As relações que transformam" }\end{array}$ \\
\hline
\end{tabular}

\section{A - Saúde, conceitos, diversidade...}

O significado de saúde para os diversos atores da pesquisa se mostrou enquanto plural dentro do contexto hospitalar, observa-se que ela se caracteriza enquanto um processo contínuo de aquisição e que envolve múltiplos determinantes sociais, todavia, quando rompido por algum evento de adoecimento, torna-se um marco que é potencializado durante ou após a internação hospitalar, deixando marcas na construção do sujeito. 
Para compreender o significado de saúde dentro de um ambiente hospitalar o olhar vai para além daquilo que é visto, sendo necessário tirar de cena os leitos e paredes brancas, os aparelhos, a correria dos profissionais, o ambiente inodoro, a rotina medicamentosa e todos os horários fixos para a higiene pessoal. Assim, é preciso ir em busca daquilo que é o sujeito em sua totalidade e dos modos em que ele se relaciona com os meios e cria seus significados.

\section{a.1) Saúde: Bem-estar versus ausência de doença}

Para os diversos sujeitos da pesquisa a ótica sobre a saúde se mostra enquanto diversificada. Observa-se que a saúde para estes sujeitos se apresenta como um conjunto complexo de inter-relações que culmina no bem-estar individual e coletivo, ainda que se mostra ligada pelo pensamento dominante de que a saúde é a ausência da doença.

A fala abaixo aponta estas mudanças que reverberam no significado do que seja saúde.

"Saúde é bem mais que uma doença em si instalada. É uma questão psicológica de bem-estar, é muito mais que o paciente estar internado, por estar com uma doença em si. Tem que ter também saúde mental, tem que ter também lazer, várias coisas, incluindo até a arrumação. Não é só o processo saúde doença. Hoje a gente já tá vendo que é bem diferente disso. A ausência da doença não é só estar instalado uma patologia, são várias coisas, um conceito muito amplo, que acho que as pessoas agora estão entendendo um pouco isso, entendendo que não é só saúde do corpo, mas a saúde da mente, também, tem que ser levada em consideração, questões econômicas, tudo, num modo geral" (Profissional D).

Pode-se observar que o significado de saúde perpassa pela compreensão das vivencias e relações dos indivíduos com o seu meio e consigo mesmo, um sentido totalitário e que envolve não somente questões de cunho físico ou puramente relacionada a doença, mas a partir da compreensão que a saúde acontece nos diversos aspectos da vida, seja de cunho emocional, psicológico, econômico, ambiental, existindo também a compreensão de um indivíduo ativo no processo, que a gerencia.

Backes et al. (2009) apontam que este modo de pensar tomou força primordialmente na conferência de Ottawa que ocorreu no ano de 1986, surgindo a partir de então o entendimento de uma saúde ampliada, positiva e de cunho multifatorial e que acontece a partir dos determinantes em saúde. Porém, é necessário refletir que o pensamento de saúde enquanto ausência de doenças ainda se encontra fortalecido nos ambientes de saúde que fazem com que esta compreensão esteja presente no cotidiano da população, como nestes outros relatos:

"Segundo a Organização Mundial da Saúde é um bem-estar físico, psicossocial e espiritual. No nosso contexto hospitalar a gente tem observado que aqui tem visto saúde como ausência de doença. Então para mim saúde é um completo bem-estar do paciente" (Profissional B).

"Saúde é qualidade de vida, bem-estar, né? Um ser humano que não está se sentindo bem, que não se sente em um local agradável ele está doente. Então, saúde é qualidade de vida, é bem-estar geral" (Cuidador E.J.S).

As falas trazem que a visão do ambiente hospitalar que enxergam a saúde como ausência de doença, seguindo a visão biomédica, enfatizada em aspectos biológicos e mecanizada do ser humano, perdendo com isso a singularidade dos indivíduos e limitando-os de suas potências. Compreende-se, portanto, que apesar da compreensão do profissional da ideia ampliada de saúde, o ambiente que se encontra, ou melhor trabalha ainda permanece no conceito reducionista (Cutolo, 2006).

Contudo, sabe-se que o atendimento em ambientes de saúde, quando seguem puramente este modelo andam numa perigosa linha tênue de procedimentos puramente técnicos que intitulam de cuidado e que no âmbito das experiências geradas criam repulsa a tais ambientes e profissionais. Para tanto, existe uma necessidade de mudança na atenção em saúde e em suas práticas, sendo necessário dar abertura para que os indivíduos sejam gerenciadores de sua saúde e capazes de contribuir com o 
cuidado que lhes é ofertado (Backes et al., 2009). Neste sentido, observa-se que o significado de saúde se encontra atrelado a totalidade da vida e a suas múltiplas inter-relações, que constroem assim o ser humano:

"Saúde é tudo, sem ela não somos nada, nem ninguém” (Paciente M.N.C).

\section{B - Humanização, entre o querer, o poder e o fazer}

Ao discutir o significado de humanização em saúde, se fala do processo de compreensão de valores e atitudes sociais que se encontram intrinsicamente ligados ao aspecto relacional no âmbito coletivo e individual. Neste sentido, se faz necessário entender que tais valores e atitudes estão sendo diretamente influenciados pela construção moral e ética de cada época, existindo uma conceituação fluida e mutável. Se faz necessário analisar de modo singular estes processos nos diversos serviços em saúde, no caso desta pesquisa, no âmbito hospitalar. Portanto, pensar na lógica de funcionamento e nos processos inter-relacionais deste local, aponta para os possíveis significados de humanização.

\section{b.1) Humanização: Empatia e ética}

Para os diversos atores desta pesquisa a humanização acontece no processo de empatia com o outro e está diretamente ligada ao aspecto relacional dos indivíduos. Consequentemente toma forma no ato de cuidar e ser cuidado, este que por sua vez, vai além do puro uso de técnicas e tecnologias e da observação unicamente biologicista do indivíduo que gera reducionismos e exclusões dos fatores subjetivos do sujeito. Neste sentido, Rios (2009) aponta que a essência da humanização é o agrupamento da técnica e tecnologia com aspectos éticos e relacionais entre todos os indivíduos do ambiente hospitalar. $\mathrm{Na}$ fala abaixo, um dos profissionais sujeito da pesquisa aponta o ideal de como precisa ocorrer os processos que evolvem o cuidado e suas relações, trazendo uma importante reflexão sobre a necessidade de humanizar o Ser Humano.

"É o processo de olhar o outro como a gente gostaria de ser olhado, é o processo de cuidar como a gente gostaria de ser cuidado [...] a gente trabalha com o que é humano, as vezes, é até estranho falar de humanização, humanizar o que deveria ser humanizado, mais é algo tão necessário que se faz discutir hoje em dia, porque a gente está perdendo, então, humanização é olhar pro outro sabendo que você poderia estar sendo olhado da mesma forma" (Profissional J.P.B.S.).

Neste sentido, a humanização se caracteriza enquanto um ato de resgate a valores humanos e éticos, que no ambiente hospitalar encontra barreiras para acontecer, sufocado em uma realidade de técnicas e procedimentos que enxerga primordialmente no ser humano uma doença a ser tratada, e que faz do hospital uma representação de dor, sofrimentos e perdas (Rios, 2009).

A humanização remete ao respeito a singularidade e a possibilidade em fazer do sujeito coautor do seu cuidado e acontece por meio de um processo relacional de trocas humanas que necessitam estar permeadas pela empatia. Neste sentido, Formiga (2012) aponta que esse valor humanitário é a capacidade humana de envolver-se com o outro a tal ponto de criar suportes de cunho afetivo ou social que venham a beneficiar a quem está sendo assistido. As próximas falas caracterizam o que seria o ato de humanizar:

“Olhar fundo pro outro, só isso mesmo! ” (Paciente J. C. S.).

"É sensibilidade, é entender que nós somos sujeitos que precisa ajudar para que a gente seja ajudado, né? É isso" (Cuidador E.J.S).

"Ser humano, ser humano com as pessoas, né não? Eu acho assim, humanidade, uns amar aos outros [...] se um está precisando de uma ajuda você chegar alí e dar a mão para ajudar, se está precisando de um cuidado, você chegar ali 
dar uma mãozinha, uma força ali para aquele paciente, para ajudar. Acho que é isso, Ser Humano, é [pausa]. Nós necessitamos um dos outros, nós não podemos viver num mundo sozinho, sempre um ajudando o outro" (Cuidador G.M.S.O).

Observou então que o significado que permeia o ato de humanizar está intimamente relacionado a sensibilidade, o cuidado integral e a valorização e respeito dos sujeitos e suas cargas históricas e sociais (Silva, Conceição \& Chagas, 2017).

\section{b.2) É direito se sentir humanizado!}

Ao falar acerca do significado de humanização enquanto direito, é necessário olhar para a Política Nacional de Humanização (PNH), responsável por inserir e abordar a temática da humanização e direcionar as ações de profissionais, gestores e usuários dentro do Sistema Único de Saúde (SUS) em toda sua rede. Observa que tal política tem como protagonismo, a corresponsabilidade e a autonomia dos sujeitos, acoplados ao modo em que se pensa e faz o cuidado (Humanizasus, 2004). Tal política propõe uma prática que vai de encontro aos modelos hegemônicos de saúde que se encontram enquadrados em uma gestão hierarquizada e por uma visão puramente biológica do sujeito e que faz do cuidado a pura aplicação de técnicas e procedimentos, onde, o sujeito é visto enquanto inferior e submisso a aquilo que lhe é dito que for melhor.

\footnotetext{
"Humanização é a garantia de direito, é a sensibilidade que a gente deve ter com o outro, porque a gente nunca sabe o dia de amanhã, ne? Nenhum ser humano até então que eu conheço e que viva em sociedade ele consegue viver sem a ajuda do outro e sem ajudar. Então humanização é a garantia de direito. Quando eu ajudo o outro eu estou garantindo o bem estar dele e com essa garantia que estou dando eu estou sendo humana, né? Para que em um futuro, também, a gente vai chegar a precisar de que outras pessoas possa estar nos ajudando" (Cuidador E.J.S).
}

Humanização seria cuidar do outro, como um todo, independente do sexo, do gênero, do estado civil, do estado religioso, do estado financeiro. A humanização tem que estar presente, coisa que ultimamente pela falta do material humano, pela falta do material médico-hospitalar tem sido dificultado e a burocracia tem sido um perrengue para evitar a humanização no nosso cuidado" (Profissional B).

Observa-se que o significado de direito a humanização se encontra intrinsicamente ligado ao dever de zelar pelo outro e de garantir que independente dos fatores que diversificam o ser humano estes serão compreendidos e valorizados, neste sentido, observa-se a perspectiva da saúde que acontece no coletivo e que depende das inter-relações com os outros sujeitos para que venha a acontecer. A cartilha do Humanizasus (2004) aponta que para que um SUS humanizado aconteça ele depende do reconhecimento de cada sujeito enquanto cidadão de direito e que é ativo na produção da saúde. Portando, reconhecer a humanização enquanto direito é fazer do usuário e dos profissionais atores protagonistas, gerenciadores e produtores de saúde.

\section{b.3) Sem condições não dá!}

Este núcleo foi construído a partir da fala de profissionais junto a observação dos espaços de trabalho enquanto eram feitas as entrevistas. Existe uma justa cobrança sobre os profissionais da saúde para que ofertem o melhor cuidado aos pacientes, todavia, são encontradas barreiras que impedem que o cuidado integral aconteça, neste sentido, as próximas falas representam uma difícil realidade vivenciada pelos profissionais.

"Condições de trabalho. Tanto para o lado do funcionário, que não adianta um funcionário mal remunerado, mal assistido, uma alimentação ofertada ao funcionário de péssima qualidade, condições até mesmo do funcionário chegar ao seu local de trabalho. Porque não dá para cuidar do outro com humanização se o próprio funcionário não se sente acolhido" (Profissional B). 
"[...] a gente sabe que tem muitos problemas na unidade, estes geram desconforto para os profissionais que estão trabalhando, às vezes, o acolhimento não acontece de uma forma plena por isso, às vezes, devido a sobrecarga de trabalho, onde, o profissional dentro da unidade fica sobrecarregado e é desvalorizado [...] então isso tudo atrapalha, porque quem está trabalhando precisa ter uma saúde psicológica boa para poder acolher, para poder entender quem está chegando doente e os familiares. Então tem que ter um preparo dos gestores do hospital com os funcionários [...]” (Profissional D).

As condições de trabalho são fatores de ordem estrutural e relacional que dialogam entre si e são altamente influenciados um pelo outro, neste sentido, quando existe um desequilíbrio nestes dois aspectos, suas consequências afetam diretamente as relações com pacientes, cuidadores e outros profissionais. Assunção (2011) aponta que a falta de condição no ambiente de trabalho, interfere diretamente no processo de cuidado e na forma com que o profissional se percebe em meio a sua prática diária, podendo gerar sentimentos negativos. Observa-se então que os profissionais apesar de compreenderem o significado de humanização não se sentem tratados dessa mesma forma, consequentemente, existe uma ruptura no campo das ideias para com a prática que gera um cuidado encarado enquanto insuficiente e incapaz de abranger a complexidade do ser humano.

Ainda neste sentido, o Ministério da Saúde por meio do caderno HumanizaSUS aponta que a humanização tem ligação direta com a valorização do trabalhador e do trabalho, onde, existe a necessidade de discutir dois pontos centrais. $\mathrm{O}$ primeiro corresponde a horizontalidade e democratização da gestão de modo que os trabalhadores estejam inclusos diretamente nos processos de gestão e consigam problematizar e produzir formas de intervir a partir da sua realidade de trabalhador e em suas condições de trabalho. $\mathrm{O}$ segundo ponto se relaciona diretamente ao enfrentamento da realidade, observando as condições de trabalho. Ler-se com isso as problemáticas enfrentadas, como baixa remuneração, os vínculos profissionais precarizados e instáveis e as condições insalubres dos postos de trabalho, que criam interferências negativas no cuidado a saúde dos que cuidam (Brasil, 2010).

\section{C - E o palhaço com o seu nariz...}

A presença dos palhaços nos hospitais se mostrou bem aceita perante aos profissionais, pacientes, cuidadores e gestores. São grupos ou indivíduos que possuem ou não formação, mas que percebem e sentem nesta arte uma possibilidade de subverter realidades, neste caso, a do hospital. O palhaço possui a capacidade de impulsionar em si mesmo habilidades positivas e consequentemente aquele que recebe a sua visita, também, é impulsionado, sendo colocado então em evidência as suas potencialidades e singularidades. O próximo núcleo busca discutir sobre o significado do palhaço no ambiente hospitalar.

\section{c.1) O palhaço enquanto ferramenta da humanização}

No núcleo "Humanização, entre o querer, o poder e o fazer" foi observado que o significado de humanização perpassa primordialmente pelo modo empático de se relacionar com o outro, neste sentido, os atores reconhecem que um dos significados do palhaço é a humanização.

Masetti (2005) aponta que o palhaço trabalha com um dos aspectos mais inerentes do ser humano, que são as relações humanas. São por elas que o processo do palhaço se inicia e traz significados para aqueles que estão recebendo a sua visita. É por meio das relações humanas que os indivíduos e coletivos se constroem, reconstroem e reinventam seus sentidos e significados perante a tudo que seja importante. Na fala abaixo pode-se compreender que o cuidador aponta a humanização como uma ação feita a partir de uma junção entre palhaços e pacientes.

"Humanização é o que foi feito aqui com palhaços é essa questão. A junção dos palhaços com o paciente, esse jeito deles quererem se introduzir para dar uma certa alegria. Para ajudar a pessoa, por que o ambiente hospitalar nunca 
é bom, nem para quem está doente e nem para quem está cuidando. Quando chega os palhaços e quando há essa abordagem é muito bom, para ele, para mim, para todos [...]" (Cuidador N.R.S).

Neste sentido, pode perceber que somente pelo puro ato de se relacionar com o outro já se é considerado humanização ou uma ação humanizada para o cuidador, na qual os palhaços trazem consigo a capacidade de subverter as relações ambientais, saindo de um espaço desagradável para os profissionais, cuidadores e pacientes e indo para um espaço mais vivo e alegre.

\section{c.2) O que estou sentindo Dr. Palhaço?}

$\mathrm{O}$ ambiente hospitalar e as suas inter-relações evocam aos autores desse espaço diversos sentimentos que muitas das vezes são negligenciados e remetem coisas negativas. Foi possível observar que a dureza das relações e dos espaços físicos hospitalares culminam em processos potencialmente traumáticos para todos os autores da pesquisa, neste sentido, o palhaço se apresenta com a sua natureza cômica e excêntrica, sendo capaz de subverter as regras limitantes postas neste ambiente. Pode-se observar quais foram os sentimentos mais presentes a partir das falas abaixo:

“Alegria contagiante, alegria, festa, vida!” (Profissional E).

"Então, traz alegria! Nunca vi um palhaço chegar aqui e continuar do mesmo jeito, aquela mesma tristeza. Eu sei que o hospital não é 24 horas só tristeza, Tem uns momentos entre profissionais, entre pacientes que tem alegria. Só que a gente vê mais sofrimento, né? É um lugar de aglomeração de doenças, de sofrimento, mas os palhaços trazem alegria, agradam o ambiente" (Profissional A.M).

"Dão alegria para as pessoas que estão doentes. Teve um senhor de 102 anos aqui, chegou uma (palhaça) animou bastante, botou aquele tomatinho no nariz dele, o nariz do palhaço e o velho ficou super feliz, sorriu [...]" (Paciente J.S.W).

Percebe-se que os sentimentos mais presentes surgem de uma ação coletiva e relacional que permitiu momentos de exaltação da vida, sendo possível compreender que a presença do palhaço possibilitou a criação de afetos para que a subjetividade do sujeito se manifestasse da forma mais plena, por meio muitas vezes do sorriso ou simplesmente da relação do palhaço com os sujeitos.

Matraca et al. (2011) apontam que o riso é uma forte ferramenta de construção de vínculos e de quebra de barreiras comumente hegemônicas dentro dos espaços de saúde. Sendo o riso benéfico somente pelo fato de fazer bem, não carecendo de outras possíveis explicações. Porém, De Castro (2005) aponta que o riso por mais simples que seja, demanda diversas conexões celebrais e relacionais para acontecer. Já no campo fisiológico do indivíduo é comprovado que o riso permite a liberação de endorfina, hormônio capaz de criar efeito analgésico que ajuda a prevenir o estresse e doenças, auxiliando na superação e ressignificação do difícil cotidiano hospitalar (Cassoli, 2016). Como pode observar no relato abaixo:

"Muda, pois tudo de repente fica feliz, ele alegra a pessoa, se a pessoa está triste, ele vem fazer a pessoa feliz, faz a pessoa sorrir. É isso!" (Paciente R.J.).

Neste sentido, a presença do palhaço colabora com o riso, a alegria e possibilita a mudança de foco do agravo em saúde e as suas formas de tratamento e traz o enfoque para a o sujeito na sua complexidade da vida e seus processos subjetivos, tornando os protagonistas de suas histórias. 


\section{c.3) "As relações que transformam".}

Este último núcleo busca refletir sobre as relações hospitalares, porém, é necessário relatar a realidade do local em que acontecia a pesquisa, indo além dos números de alas e leitos como foi trazido na metodologia. É um hospital em processo de total mudança, saindo de uma gestão municipal regional e mudando para uma gestão ligada a empresa de serviços hospitalares universitários. Além da troca de aparelhos e toda reorganização física nos espaços, existia uma troca de trabalhadores da saúde que gerava apreensão aos que estavam, pois a qualquer momento poderiam ser demitidos.

A pesquisa traz este recorte da realidade visando proporcionar uma melhor contextualização, pois todas estas questões trazidas anteriormente criavam uma certa apreensão por parte de quem se encontrava no hospital e isto possivelmente teve forte influência nas relações entre os indivíduos e o meio no qual se encontravam. A partir disso, é possível compreender o papel do palhaço, como pode observar nas falas abaixo:

"Pra mim muda tudo! Porque o paciente estava aqui, dormindo, de repente entrou eles aqui cantando, animando, no mesmo instante ele já estava rindo, achando bonito, conversando, contando que estava meio triste, que estava sentindo dores. Isso ali levantou o astral dele, pra ele foi tudo. E para nós também como acompanhante que é filha ne? A gente se animou, até fiquei emocionada, choramos, porque isso é Amor! É ver o teu carinho com o paciente que estava acamado, triste e reanimou ele" (Cuidador G.M.S.O).

"Muda na questão dos pacientes, eles se sentem valorizados, sentem que tem alguém que está se importando com eles, porque tem muitos aqui que nem acompanhante tem, fica sozinho, fica sem a família, então pra eles aquele momento de atenção é muito importante, e assim, entre os profissionais também é muito bom, porque a gente gosta. É uma dinâmica legal, diferente, muda a rotina toda. Então é super importante, e acho que é um projeto que deve se investir bastante, manter sempre, melhorar cada vez mais" (Profissional D).

"Claro que sim! Muda muitas coisas. Sem um palhaço aqui a sala era esquisita, todo mundo triste. Quando eles entraram, foram outro clima, tudo de bom" (Paciente J.C.S).

A partir das ações do palhaço pode se compreender a potência que existe nas relações humanas, sendo capaz de recriar a realidade e fazer nascer bons sentimentos, permitindo uma valorização de cada sujeito dentro deste espaço, independente do papel que desempenha, quer seja um paciente, um familiar ou o profissional, cada um destes conseguia durante a relação com o palhaço se mostrar mais ativo, onde cantavam e dançavam, e algumas vezes até choravam só por receberem um abraço, permitindo que aquele ambiente, antes estéril de sentimento, inundasse de vida e significado.

\section{Considerações Finais}

O desenvolvimento desta pesquisa possibilitou compreender que existe na sociedade uma mudança no pensamento coletivo acerca do entendimento dos conceitos de saúde dentro do contexto hospitalar, onde, surgiu um significado atrelado ao bem-estar, as inter-relações com os determinantes sociais em saúde, junto ao reconhecimento da subjetividade dos indivíduos e a valorização dos potenciais de cada um. Corrobora então com o significado apreendido acerca da humanização nesta pesquisa, que se relaciona com a compreensão de si e do outro, enquanto ser humano. Observa-se que estes processos acontecem a partir do resgate dos valores humanos e éticos que possibilitam compreender o ser humano em sua complexidade e totalidade.

A pesquisa aponta, ainda, que o palhaço, possui como significado primordial a humanização e este significado é construído a partir das características e ações do palhaço, neste sentido, a subversão das relações hegemônicas e a possibilidade de relações horizontais e empáticas, que reconhecem os sujeitos a partir das suas singularidades e potencialidades, são capazes de despertar nas pessoas sentimentos positivos, como o da alegria, do amor e da felicidade, criando espaços onde a vida é festejada, independente da patologia vivenciada. Portanto, o palhaço contribui com a ressignificação dos ambientes e das 
relações entre os sujeitos do hospital, haja vista que por meio das suas ações possibilita criar e fortalecer relações, colocando os sujeitos frente a frente enquanto seres humanos em sua essência.

\section{Referências}

Aguiar, W. M. J. (2000). Reflexões a partir da psicologia sócio-histórica sobre a categoria “consciência”. Cadernos de Pesquisa, 110, 125 -142.

Aguiar, W. M. J. \& Ozella, S. (2006). Núcleos de Significação como Instrumento para a Apreensão da Constituição dos Sentidos. 231. <http://www.scielo.br/pdf/pcp/v26n2/v26n2a06.pdf>.

Albuquerque, C. M. S. \& Oliveira, C. P. F. (2002). Saúde e doença: significações e perspectivas em mudança. Millenium.

Assunção, A. A. (2011). Condições de Trabalho e Saúde dos Trabalhadores da Saúde. In: Minayo Gomes, C.; Machado, J. M. H.; Pena, P. G. L. Saúde do trabalhador na sociedade brasileira contemporânea.

Backes, M. T. S., Rosa, L. M., Fernandes, G. C. M., Becker, S. G., Meirelles, B. H. S. \& Santos, S. M. A. (2009). Conceitos de saúde e doença ao longo da história sob o olhar epidemiológico e antropológico. Revista de Enfermagem da Universidade Estadual do Rio de Janeiro, 17(1).

Batistella, C. (2007). Abordagens contemporâneas do conceito de saúde. In: Fonseca AF, Corbo AD, organizadores. O território e o processo saúde-doença. Rio de Janeiro: EPSJV, Fiocruz, p. 51-86.

Brasil. (1986). Ministério da Saúde. $8^{a}$ Conferência Nacional de Saúde in. Anais da $8^{a}$ Conferencia Nacional de Saúde. Brasília: MS, p.4.

Brasil. (2010). Ministério da Saúde. Secretaria de Atenção à Saúde. Núcleo Técnico da Política Nacional de Humanização. HumanizaSUS: Documento base para gestores e trabalhadores do SUS / Ministério da Saúde, Secretaria de Atenção à Saúde, Núcleo Técnico da Política Nacional de Humanização. - 4. ed. 4. reimp. - Brasília : Editora do Ministério da Saúde.

Brasil. (2010). Ministério da Saúde. Secretaria de Atenção à Saúde. Política Nacional de Humanização. Formação e intervenção / Ministério da Saúde, Secretaria de Atenção à Saúde, Política Nacional de Humanização. Ministério da Saúde. 242 p. - (Série B. Textos Básicos de Saúde) (Cadernos HumanizaSUS ; v. 1)

Canguilhem, G. (2009). O normal e o patológico. Tradução de Mana Thereza Redig de Carvalho Barrocas; revisão técnica Manoel Barros da Motta; tradução do posfácio de Piare Macherey e da apresentação de Louis Althusser, Luiz Otávio Ferreira Barreto Leite. - 6.ed. rev. - Rio de Janeiro: Forense Universitária.

Cassoli, T. (2016). Humanização, psicologia e riso: produção de liberdade e processos de subjetivação. Revista Polis e Psique, 6(2), $109-133$.

Cutolo, J. R. A. (2006). Modelo Biomédico, Reforma Sanitária e a Educação Pediátrica. Arquivos Catarinenses de Medicina 35(4).

Czeresnia, D. (2003). O conceito de saúde e a diferença entre prevenção e promoção. Promoção da saúde: conceitos, reflexões, tendências, 3 , 39-54.

De Ayalla, R. A. F. \& Nunes Filho, W. J. (2013). A utilização do palhaço no ambiente hospitalar. OuvirOUver, 9(1), 72-81.

De Castro, A. V. (2005). O Elogio da Bobagem - palhaços no Brasil e no mundo. Editora Família Bastos.

EBSERH. (2015). Dimensionamento dos serviços assistenciais do hospital universitário de lagarto da universidade federal de sergipe -HUL/UFS, Brasília. 18 de setembro. http://www.ebserh.gov.br/documents/15796/855348/Dim+Assist+final+HUL+UFS+180915.pdf/a93f37ca-683f-4aca-93e8-8be0f05ff7e5

Formiga, N. S. (2012). Os estudos sobre empatia: Reflexões sobre um construto psicológico em diversas áreas científicas. Revista eletrônica psicologia. O Portal dos Psicólogos, v. 1, p. 1-25.

Freitas, M. T. A. (2000). As apropriações do pensamento de Vygotsky no Brasil: um tema em debate. Psicologia da Educação, (10/11), 09-28. file://C:/Users/Raphaela/Downloads/41383-Texto\%20do\%20artigo-116587-1-10-20190208.pdf.

Freitas, M. T. A. (2002). A abordagem sócio-histórica como orientadora da pesquisa qualitativa. Cadernos de Pesquisa (116), 29 https://www.scielo.br/j/cp/a/KnJW3strdps6dvxPyNjmvyq/abstract/?lang=pt\#

Graças, E. M. (1997). A experiência da hospitalização uma abordagem fenomenológica. REME rev. min. enferm, 1(1), 21-26.

HumanizaSUS. (2004). UMANIZASUS: Política Nacional de Humanização: a humanização como eixo norteador das práticas de atenção e gestão em todas as instâncias do SUS / Ministério da Saúde, Secretaria-Executiva, Núcleo Técnico da Política Nacional de Humanização. Ministério da Saúde. https://bvsms.saude.gov.br/bvs/publicacoes/humanizasus_documento_gestores_trabalhadores_sus.pdf.

Júnior, A. A. S. (2011). O trickster e o palhaço: a permanência da transgressão. http://www.ip.usp.br/laboratorios/lapa/versaoportugues/2c44a.pdf.

Masetti, M. (2005). Doutores da ética da alegria. Interface-Comunicação, Saúde, Educação, 9(17), 453-458.

Matraca, C. M. V., Wimmer, G. \& Araújo, J. T. C. (2011). Dialogia do riso: um novo conceito que introduz alegria para a promoção da saúde apoiando-se no diálogo, no riso, na alegria e na arte da palhaçaria. Ciência \& Saúde Coletiva, 16(10).

Minayo, M. C. S. \& Sanches, O. (1993). Quantitativo-Qualitativo: Oposição ou Complementaridade? Caderno de Saúde Pública, 9 (3): $239-262$.

Ministério da Saúde. (2008). HumanizaSUS: documento base para gestores e trabalhadores do SUS, 18. 
Research, Society and Development, v. 11, n. 2, e59411226222, 2022

(CC BY 4.0) | ISSN 2525-3409 | DOI: http://dx.doi.org/10.33448/rsd-v11i2.26222

OMS. (1946). Organização Mundial da Saúde. Constituição da Organização Mundial da Saúde, adotada pela Conferência Internacional de Saúde, realizada em Nova Iorque de 19 a 22 de julho, p.1.

Rios, I. C. (2009). Caminhos da humanização na saúde: prática e reflexão / Izabel Cristina Rios. Áurea Editora.

Scliar, M. (2007). História do conceito de saúde. Physis, 17(1), 29-41.

Serra, J. (2001). Programa nacional de humanização da assistência hospitalar. Ministério da Saúde, Brasília/DF, 30, 9.

Silva, C. P. R., Conceição. A. P. \& Santos, C. A. P. (2017). Clown-o palhaço como intervenção e humanização em saúde. Journal of Health \& Biological Sciences, 5(4), 352-359.

Thebas, C. (2005). O livro do palhaço. Ed. Companhia das Letrinhas. 